\title{
Assessment of Noise Pollution along Two Main Avenues in Curitiba, Brazil
}

\author{
Paulo Henrique Trombetta Zannin, Felipe do Valle, Eriberto Oliveira do Nascimento \\ Laboratory of Environmental and Industrial Acoustics and Acoustic Comfort, Mechanical Engineering Department, \\ Federal University of Paraná, Curitiba, Brazil \\ Email: paulo.zannin@gmail.com
}

How to cite this paper: Zannin, P.H.T., do Valle, F. and do Nascimento, E.O. (2019) Assessment of Noise Pollution along Two Main Avenues in Curitiba, Brazil. Open Journal of Acoustics, 9, 26-38. https://doi.org/10.4236/oja.2019.92003

Received: February 22, 2019

Accepted: June 18, 2019

Published: June 21, 2019

Copyright (c) 2019 by author(s) and Scientific Research Publishing Inc. This work is licensed under the Creative Commons Attribution International License (CC BY 4.0).

http://creativecommons.org/licenses/by/4.0/

c) (i) Open Access

\begin{abstract}
In this study, noise pollution assessments were performed along Marechal Deodoro Avenue and Batel Avenue, which are two major thoroughfares in the city of Curitiba, Brazil. Eleven points were evaluated at Batel Avenue and 16 points at Marechal Deodoro Avenue. The results of the noise level measurements and the calculation of noise maps indicated that both thoroughfares are acoustically polluted. The simulated and measured noise levels, in the 27 evaluated points, exceed the limits established by law 10,625 of the city of Curitiba, which establishes acceptable levels for the comfort of the population in the external environment. With regard to the traffic composition in the areas under study, the vehicle flow was found to consist mostly of light vehicles, representing $88 \%$ of the total flow along Batel Avenue and $85 \%$ on Marshal Deodoro Street. Based on the noise maps and measured noise levels, it was found that the entire length of Marshal Deodoro Avenue and Batel Avenue are strongly affected by street noise, which is readily explained by the constant traffic, high vehicle flow (number of vehicles/hour) and high vehicle speed at some points of these thoroughfares.
\end{abstract}

\section{Keywords}

Noise Pollution, Noise Mapping, Sound Pressure Levels, Noise

Measurements, Urban Noise

\section{Introduction}

Urban noise is a permanent problem in the modern world, which is why there is an increasingly pressing need for quiet and calm areas for urban populations. Reference [1] emphasizes that "Special attention should be given to quiet areas and their relationship to human health and environmental health." Reference [2] 
points out that "The acoustic quality of a city depends not only on the absence of noise but also on the presence of quietness and liveliness." Similarly, in [3] discuss "The importance of public spaces in lowering urban traffic noise. Acoustic simulations indicated that traffic-related noise is dissipated in open spaces, such as public squares." Moreover, according to [3], public parks are places of quietness and well-being for urban populations. Reference [2] also emphasize that the question is not whether a city is noisy or not, but rather whether its residents have access to quiet spaces, i.e., a quiet house and neighborhood, as well as quiet urban spaces. An example of such spaces is public parks, as indicated [3].

In Germany, [4] state that: "1) The main source of noise in Germany comes from traffic noise; 2) 70\% of Germans feel annoyed by noise, 3) Nighttime noise as low as $40 \mathrm{~dB}(A)$ can lead to health problems, 4) 10\% of homes are exposed to equivalent sound pressure levels, Leq, higher than 66 - $70 \mathrm{~dB}(A)$ ".

Still in Germany, [4] state that: "Traffic noise studies show that there is a connection between the risk of heart attack and exposure to noise. The number of heart attacks among adult men was found to increase, starting from a daily equivalent sound pressure level of $>60 d B(A)$ generated by traffic noise. Germany's Federal Environment Agency estimates that 4000 annual cases of heart attacks in the country are correlated with traffic noise". Reference [4], also report on research in Sweden, where "Long-term studies from Sweden suggest, that permanent street noise exposure above $50 \mathrm{~dB}(A)$, increases the risk of having a heart attack by up to $40 \%$ ".

Then, a noise impact study was conducted to determine the environmental impact of noise pollution along two main thoroughfares in the city of Curitiba, Brazil, based on noise measurements and the calculation of noise maps. The first one was Marshal Deodoro Avenue, which is about $3.2 \mathrm{~km}$ long. This is one of the city's most well-known roads, along which hundreds of people circulate every day. The second street is a major avenue that begins in the Batel district under the name of Bishop Dom José Street and ends in the center of town under the name of Dr. Pedrosa Street. This avenue, which is about $2.7 \mathrm{~km}$ long, is commonly known as Batel Avenue.

\section{Methods}

\subsection{Analysis of Environmental Noise Emission Limits}

For the noise impact study, in situ measurements of the equivalent sound pressure levels, Leq, were taken and noise maps were also calculated. The Brazilian technical standard NBR 10151 establishes acceptable noise levels for urban areas [5].

Curitiba also has its own law against noise pollution, i.e., Law 10,625/02, which establishes permissible noise levels in various areas of the city. The law establishes permissible noise levels for three time periods: 1) Daytime-From 7:01 am to 7:00 pm, 2) Evening-From 7:01 to 10:00 pm, and 3) NighttimeFrom 10:01 pm to 07:00 am. Therefore, Law 10,625/02 establishes the maximum 
permissible noise levels according to land use zoning and time of day, as listed in Table 1 [6].

Curitiba Municipal Law No. 9800 is another important law, which establishes regulations on zoning, land use and occupation in the municipality of Curitiba, sub-dividing it into various types of zones, such as: Central Zone (CZ), Special Educational Zone (SEZ), Industrial Zone (IZ), Residential Zones-RZ (RZ1, RZ2, RZ3), Batel Residential Zone (BRZ), Green Areas (GA), Mixed Use Zone (RZ4), and others [7].

\subsection{Noise Measuring Points}

Marshal Deodoro Avenue is about 3000 meters long. Noise was monitored and measured along this avenue at 16 noise measuring points set approximately 200 meters apart. Zoning in this region is mixed-use, as there are numerous residential buildings as well as a large number of commercial establishments. In the area further away from the center there is a predominance of special purpose buildings such as regular and luxury apartment houses, although there are also many commercial properties.

Batel Avenue is about 2700 meters long. Noise was monitored and measured along this avenue, at 11 noise measuring points set approximately 200 meters apart. The measuring points were distributed starting on Bispo Dom José Street and ending on Dr. Pedrosa Street. Batel Avenue is considered a mixed-use zone since it contains not only residential apartment buildings but also commercial establishments.

The entire length of Marechal Deodoro Avenue passes through the neighborhoods of Alto da Rua XV and Centro. According to Law No. 9800 [7], this thoroughfare passes through three different types of zones, RZ3 (Residential Zone 3); RZ4 (Residential Zone 4) and CZ (Central Zone) (see Table 1). In the aforementioned zones, monitoring points 1 to 10 are located in residential areas where, according to Law No. 10,625 [6], the maximum permissible daytime noise levels that reach the building façades should not exceed $55 \mathrm{~dB}(\mathrm{~A})$ in RZ3

Table 1. Noise emission limits established by Curitiba Municipal Law 10625 (2002).

\begin{tabular}{cccc}
\hline Zones of use & $\begin{array}{c}\text { Daytime } \\
\text { 7:01 am-7:00 p.m. } \\
\text { Leq dB(A) }\end{array}$ & $\begin{array}{c}\text { Evening } \\
\text { 7:01 am-22:00 p.m. } \\
\text { Leq dB(A) }\end{array}$ & $\begin{array}{c}\text { Nighttime } \\
\text { 22:01 p.m-7:00 a.m. } \\
\text { Leq dB(A) }\end{array}$ \\
\hline $\begin{array}{c}\text { Residential zone } \\
\text { (RZ1, RZ2, RZ3) } \\
\text { and Batel Residential } \\
\text { Zone (BRZ) }\end{array}$ & $55^{\mathrm{a}}$ & 50 & 45 \\
$\begin{array}{c}\text { Mixed Use Zone (RZ4) and } \\
\text { Special Educational Zone (SEZ) } \\
\text { Central Zone (CZ) }\end{array}$ & 60 & 55 & 50 \\
$\begin{array}{c}\text { Special Zone-BR 116 } \\
\text { (Green Line) }\end{array}$ & 65 & 60 & 55 \\
Industrial and services district & 70 & 60 & 55 \\
\hline
\end{tabular}

a. Equivalent sound pressure level, Leq in $\mathrm{dB}(\mathrm{A})$. 
and $65 \mathrm{~dB}(\mathrm{~A})$ in $\mathrm{RZ} 4$. Monitoring points 11 to 16 , on the other hand, are situated in the region comprising the central zone $(\mathrm{CZ})$, where the maximum permissible daytime noise level is $65 \mathrm{~dB}(\mathrm{~A})$.

\subsection{Measurement and Analysis of Environmental Noise}

Street level noise was measured at each measuring point, perpendicularly to the axis of the street, at a distance of approximately 1.2 meters from the ground and at 2 meters distance from other reflecting surfaces such as house walls, boundary walls, etc. Vehicle counts were also made concomitantly to these noise measurements. Each measurement lasted 10 minutes, as per the standards presented in the international literature [8] [9] [10] [11]. The data collected were: 1) Counts of light vehicles, heavy vehicles and motorcycles; 2) Equivalent sound level Leq in $\mathrm{dB}(\mathrm{A})$. The measurements were taken in the daytime on weekdays, using the following devices: 1) a B\&K 2250 sound level meter, 2) a B\&K 4231 sound level calibrator, and 3) Predictor version 8.11 noise mapping software. The noise levels measured in the areas under study were compared to the noise limits established by Curitiba Municipal Law No. 10,625/02.

\subsection{Noise Maps}

Noise maps offer a broad view of the problem generated by noise pollution. They also enable scenarios to be simulated in the search for alternatives to reduce environmental noise. The use of Predictor software involved the following steps: 1) Choice of the method of calculation trough ISO 9613.1/2 Road, 2) Insertion of contour lines on the maps, 3) Insertion of orthophotos to draw buildings and vegetation by hand, 4) Insertion of the vehicle flow and the speed of each type of vehicle, and 5) Choice of the area of calculation and the grid size. Predictor ${ }^{\circledR}$ software requires a grid noise map to calculate maps. The lower the grid resolution is, the greater the accuracy and the longer the calculation time. The grid should not exceed $10 \mathrm{~m} \times 10 \mathrm{~m}$ to calculate maps of urban agglomerations [12]. For this reason, a $5 \mathrm{~m} \times 5 \mathrm{~m}$ grid was adopted [13] [14]. The grid height used here was $4 \mathrm{~m}$, as recommended in the current bibliography [15] [16].

To calibrate the model, we used as reference the recommendations of the current literature, which states that the differences between measured and simulated data are accepted when they fall within the range of up to $\pm 4.6 \mathrm{~dB}(\mathrm{~A})$ [9] [11] [13] [15] [17]. Reference [18] state that a difference of up to $5 \mathrm{~dB}(\mathrm{~A})$ between measured and simulated data is acceptable.

Also, in [19] places as a condition to calibrate the model of noise maps, that the difference between the measured and calculated values should be in the range of $\pm 3 \mathrm{~dB}(\mathrm{~A})$.

\section{Results}

\subsection{Model Calibration Results}

To calibrate the model, we used as reference the recommendations of the current 
literature, which states that the differences between measured and simulated data are accepted when they fall within the range of up to $\pm 4.6 \mathrm{~dB}(\mathrm{~A})$. Then, Figure 1 shows the differences between measured and simulated data.

A comparison of the measured and calculated values indicates that all the measuring points lie within the expected range. Figure 2 shows the calibration curves for the noise map model and shows its respective models' equations with linear correlation $\mathrm{R}^{2}$ of 0.819 and 0.878 to Batel Avenue and Marshal Deodoro Avenue, respectively.

The traffic composition in the areas under study consisted predominantly of light vehicles, 88\% traveling along Marshal Deodoro Avenue, and 85\% along Batel Avenue. Motorcycles represented 9\% of the traffic composition on Batel Avenue and $11 \%$ on Marshal Deodoro Avenue, respectively. On the other hand, the flow of heavy vehicles consisted mainly of public transport buses, with rare exceptions when a few trucks were observed. As for total vehicle flow, trucks corresponded to 3\% on Batel Avenue and 4\% on Marshal Deodoro Avenue.

Then, Figure 3 describes the traffic composition on the two avenues during one hour of measurement at each evaluation point. Most of the vehicle flow comprises light vehicles. However, heavy vehicles must also be taken into account because of the high noise levels they generate. Another evaluated parameter was the average speed of vehicles on the streets. The average estimated speed was $60 \mathrm{~km} / \mathrm{h}$ for light vehicles and motorcycles and $50 \mathrm{~km} / \mathrm{h}$ for heavy vehicles.

The average speed observed at most of the monitoring points was about 60 $\mathrm{km} / \mathrm{h}$, which was considered normal, since that is the legal speed limit established for these thoroughfares. The asphalt paving in the evaluated sections of these roads was in good condition. It should be noted that there are speed bumps and radars on both of these avenues. Based on computational simulations and in situ measurements, this study found that the traffic noise in the areas under study is constant and intense. The areas under study are strongly affected by traffic noise.

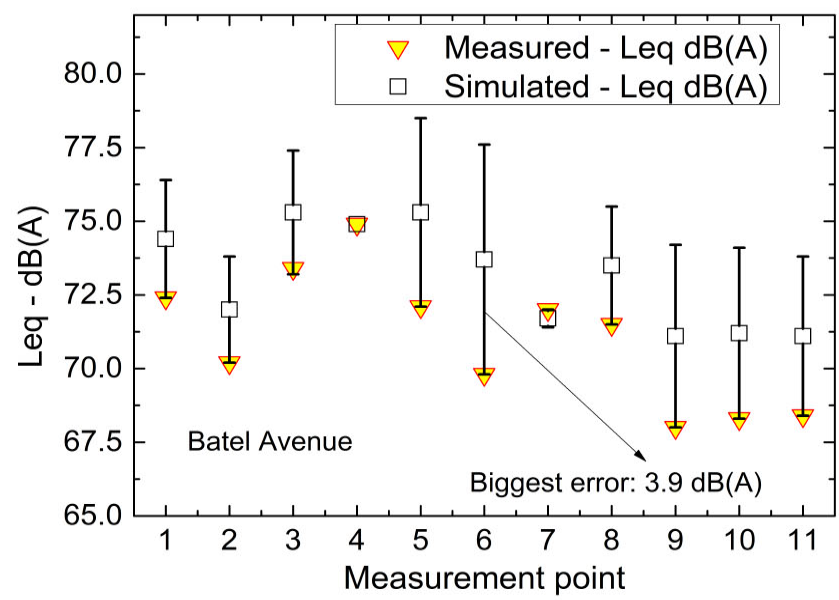

(a)

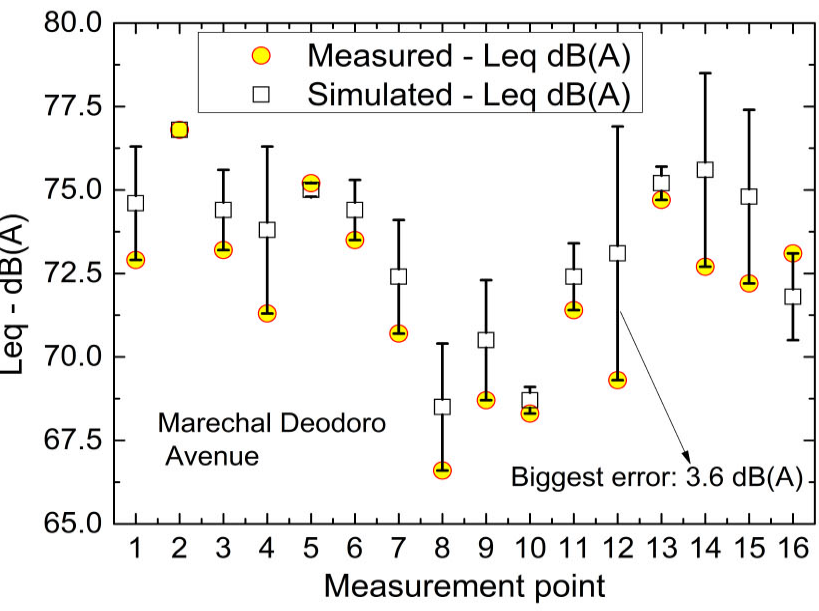

(b)

Figure 1. Sound pressure levels difference for measured and simulated values for Batel Avenue and Marechal Deodoro Avenue. 


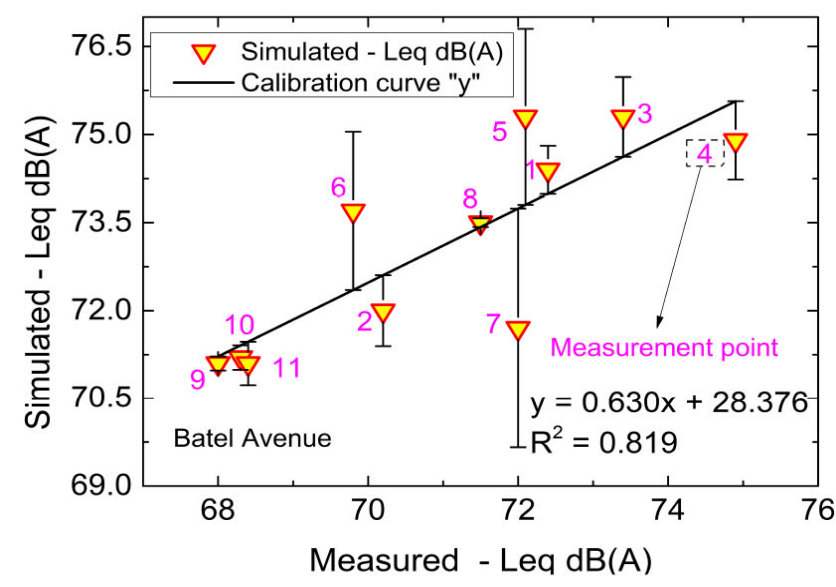

(a)

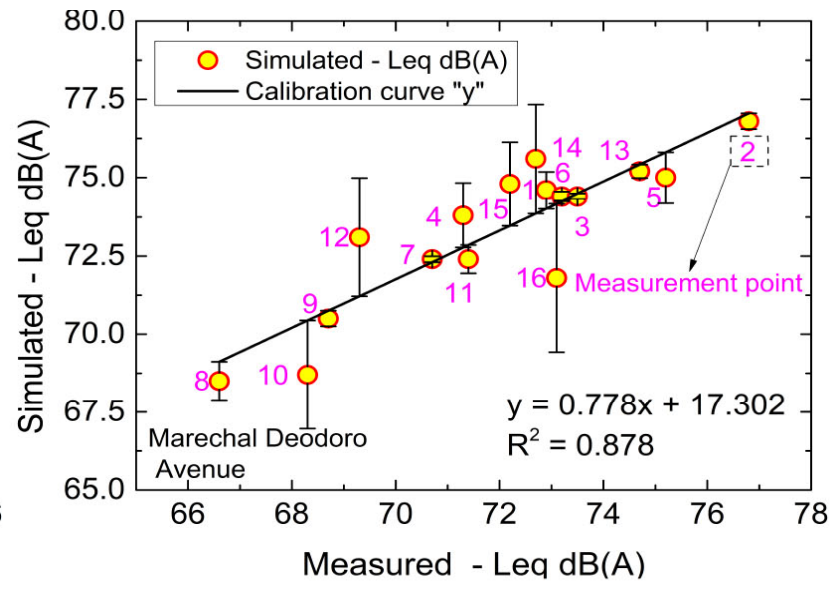

(b)

Figure 2. Calibration model for Batel Avenue and Marechal Deodoro Avenue.

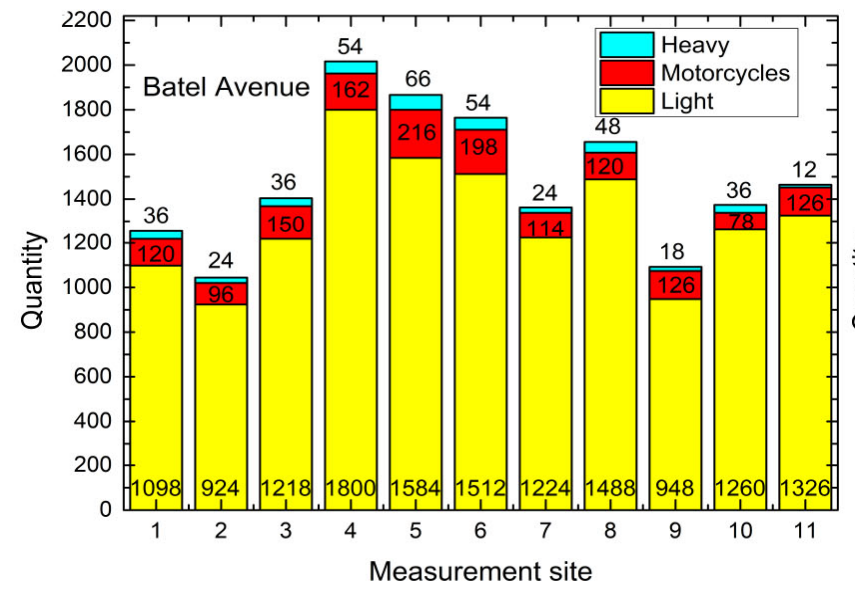

(a)

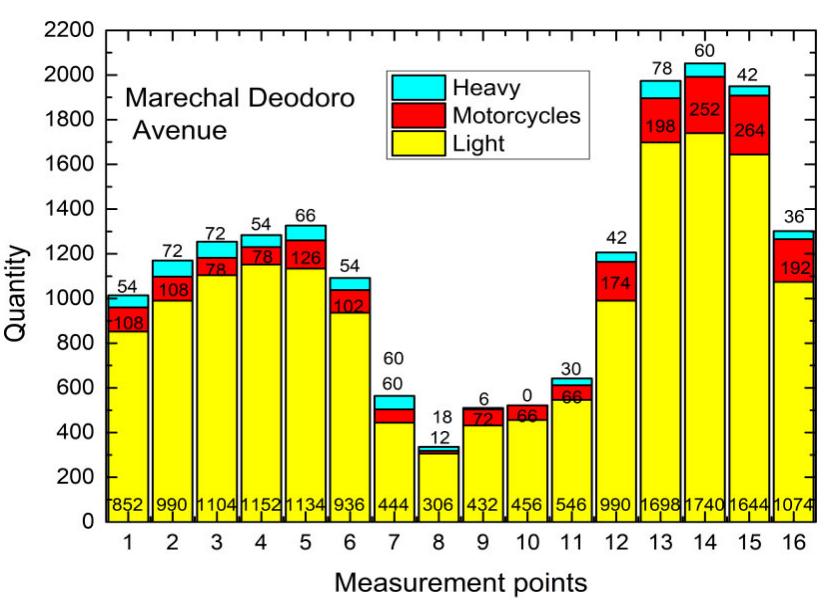

(b)

Figure 3. Traffic composition in terms of heavy, motorcycles and light vehicles.

\subsection{Noise Maps Results}

For Batel Avenue, the first noise map, in Figure 4(a), shows the equivalent sound pressure levels, Leq, along the entire road. For Marechal Deodoro Avenue, Figure 4(b), shows the equivalent sound pressure levels, Leq, along the entire road.

These maps present a color scale that indicates the noise levels along the roads and renders these noise levels. Figure 5 shows the noise map on a stretch of Batel Avenue. Figure 6 shows the noise map on a stretch of Marshal Deodoro Avenue.

Subsequently, noise maps are important aids to support measures to control and reduce noise pollution, since they provide a better overall view of noise levels at evaluated sites.

\section{Discussions}

A comparison of the legal noise limits and the simulated and the measured sound pressure levels, at each point (see Figure 7) indicates the existence of 


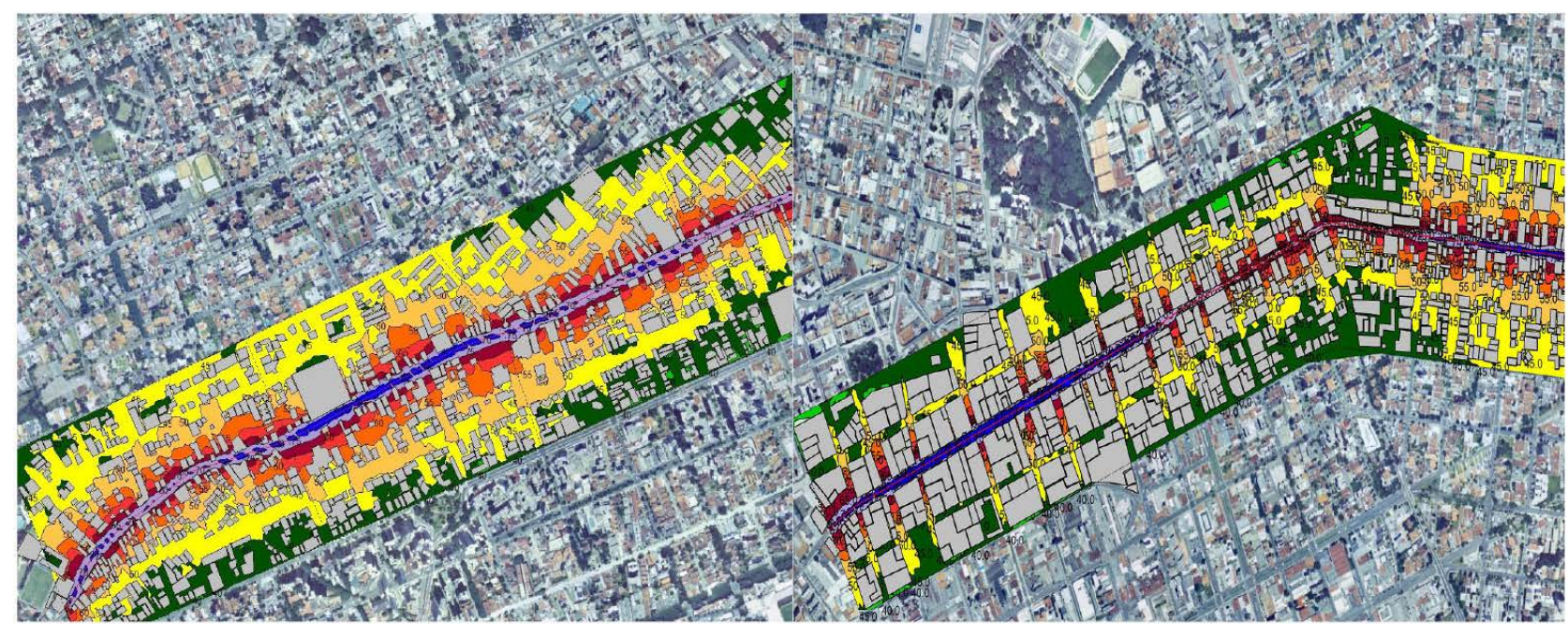

(a)

(b)

Figure 4. Noise map along the entire stretch of Batel Avenue and Marshal Deodoro Avenue.

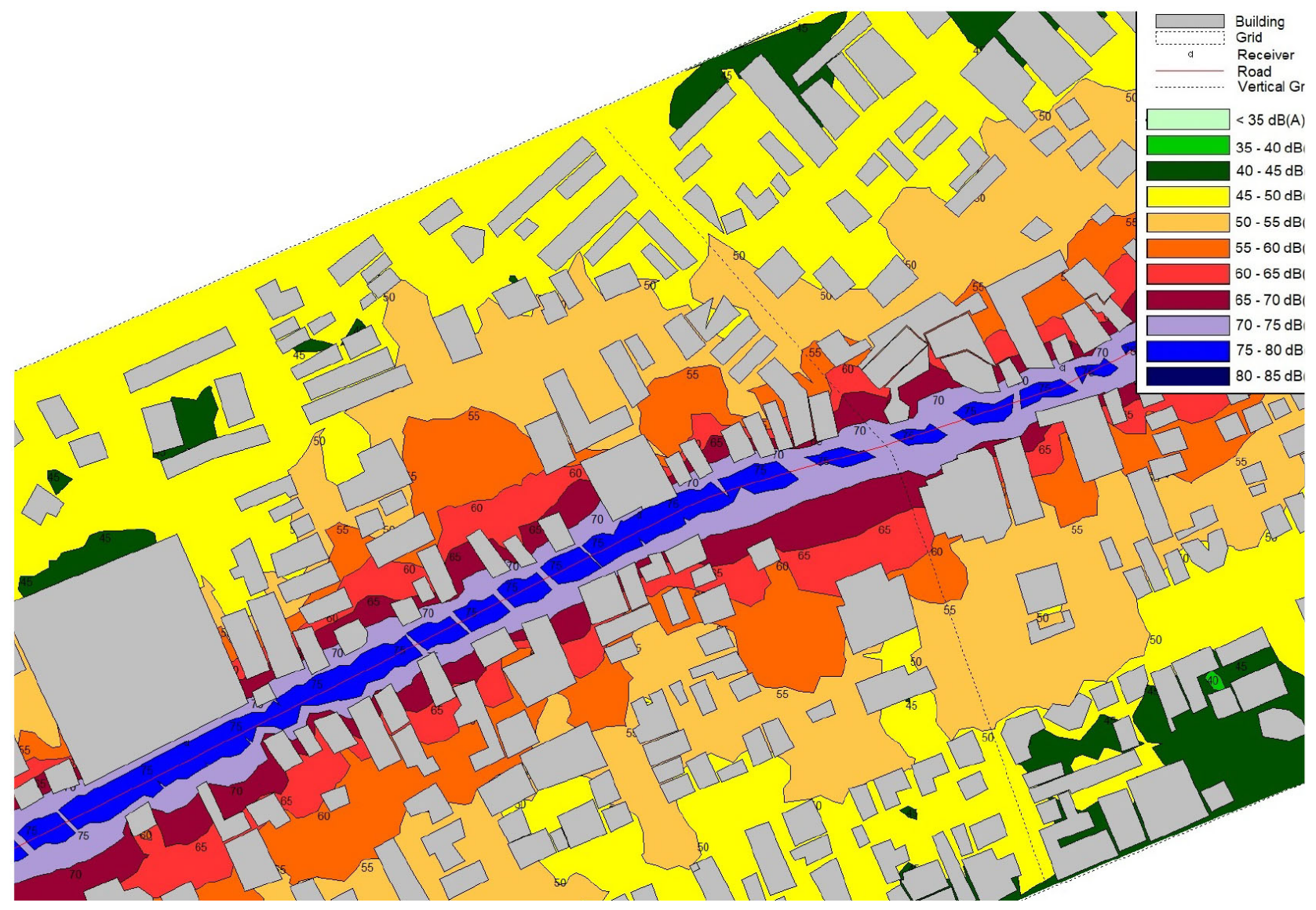

Figure 5. Noise map on a stretch of Batel Avenue.

noise pollution in the areas around the evaluated points, since, according to the measurements and simulations, the noise levels at all the points exceed the legal limits. 


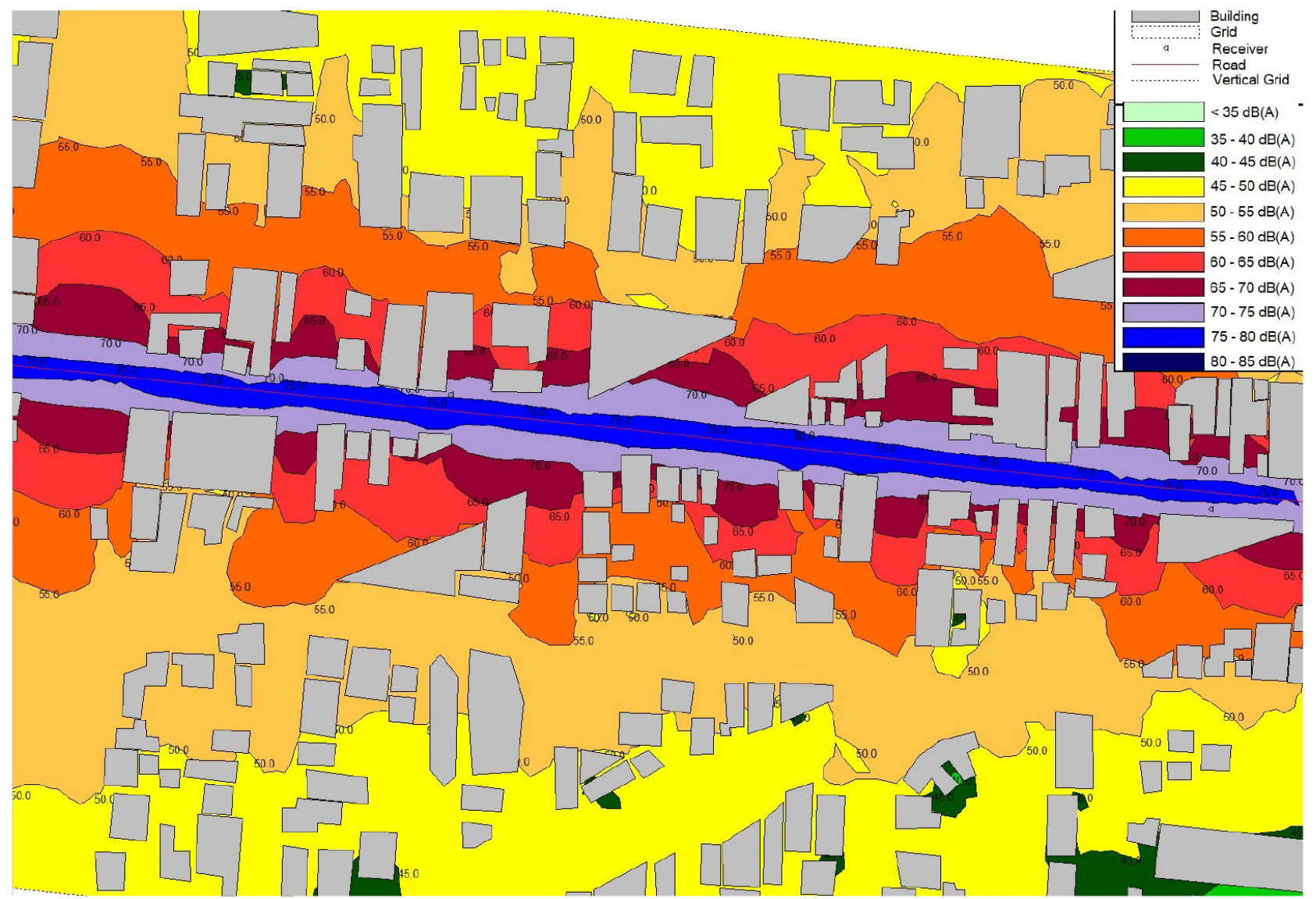

Figure 6. Noise map on a stretch of Marshal Deodoro Avenue.

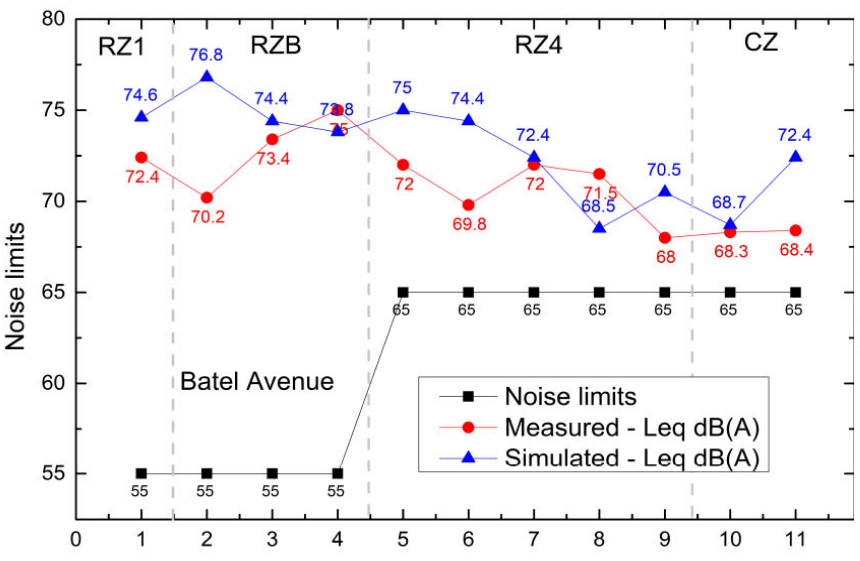

(a)

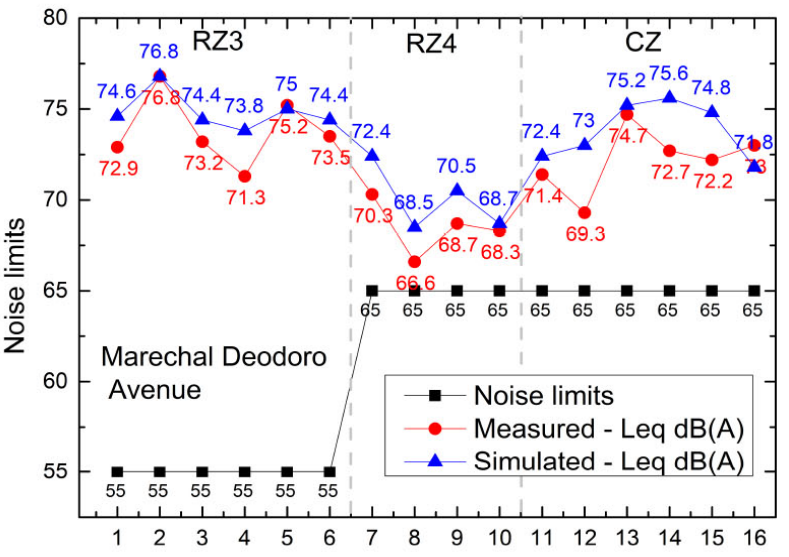

(b)

Figure 7. Noise limits according to the zoning law for Batel Avenue and Marechal Deodoro Avenue.

By analyzing each point measured in Figure 7(a) and Figure 7(b), it can be seen that the equivalent sound pressure levels are above those recommended by the Curitiba Municipal Law No. 10,625 (2002). All measured values are well above the established limits for the Urban Areas covered by the two avenues (see Table 1). The recommended values for the Urban Zones studied here are Leq $=$ 
$55 \mathrm{~dB}(\mathrm{~A})$ and Leq $=65 \mathrm{~dB}(\mathrm{~A})$.

Batel Avenue passes through three different neighborhoods. Most of its length is located in the Batel neighborhood, but a small stretch of this street is located in the Centro and Seminário neighborhoods. This avenue passes through four different types of zones; namely, RZ1, RZB, RZ4 and CZ (see Table 1).

The maps in Figures 8 and Figure 9 indicate the noise levels that reach the façades of buildings located in so-called "Quiet Zones", which encompass, for example, hospitals and schools. In these "Quiet Zones", the noise limits for RZ1 (see Table 1) must be met within a radius of 200 meters around these establishments.

In Figure 8, note that noise levels at the façades of the school range predominantly from 65 to $70 \mathrm{~dB}(\mathrm{~A})$ and from 70 to $75 \mathrm{~dB}(\mathrm{~A})$. These levels far exceed the daytime noise level of $55 \mathrm{~dB}(\mathrm{~A})$ permitted by the municipal law.

The noise around hospitals in the city of Curitiba and other urban areas was also studied by [20] [21]. In both studies, sound levels outside hospitals were measured above those recommended by Law 10.625 [6]. This shows that, in practice, there is no control of these levels by the public agents and as a consequence, there may be several problems for both patients and members of the medical staff of these hospitals ranging from "delay in the recovery of patients as to the stress of the medical team" [22].

Figure 9 shows that the noise levels reaching the front facades of the hospital vary mostly from 65 to $70 \mathrm{~dB}(\mathrm{~A})$, while those reaching the sides vary from 60 to $65 \mathrm{~dB}(\mathrm{~A})$.

According to data from the 2010 Demographic Census of the Institute of Research and Planning of Curitiba [23], Batel's neighborhood, where Batel Avenue passes, has a population of 10,878 inhabitants, of which $70.8 \%$ are between 15 and 64 years, and $16.7 \%$ over 64 years. The Central Zone, through which Batel Avenue is also located, is one of the 10 neighborhoods in the city, with the highest percentage of elderly people. According to the WHO, this group of people is classified as a vulnerable group and special attention to their health regarding noise must be considered [24].

The results of this study indicate that both thoroughfares-Marshal Deodoro Avenue and Batel Avenue, which are of immense importance for urban mobility

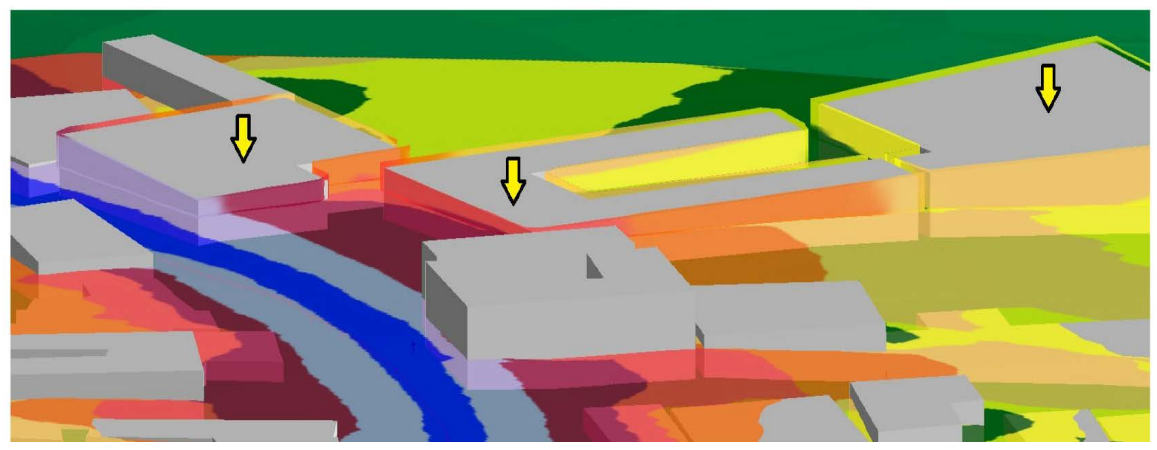

Figure 8. Noise levels that reach the facade of the Marista Paranaense School. 


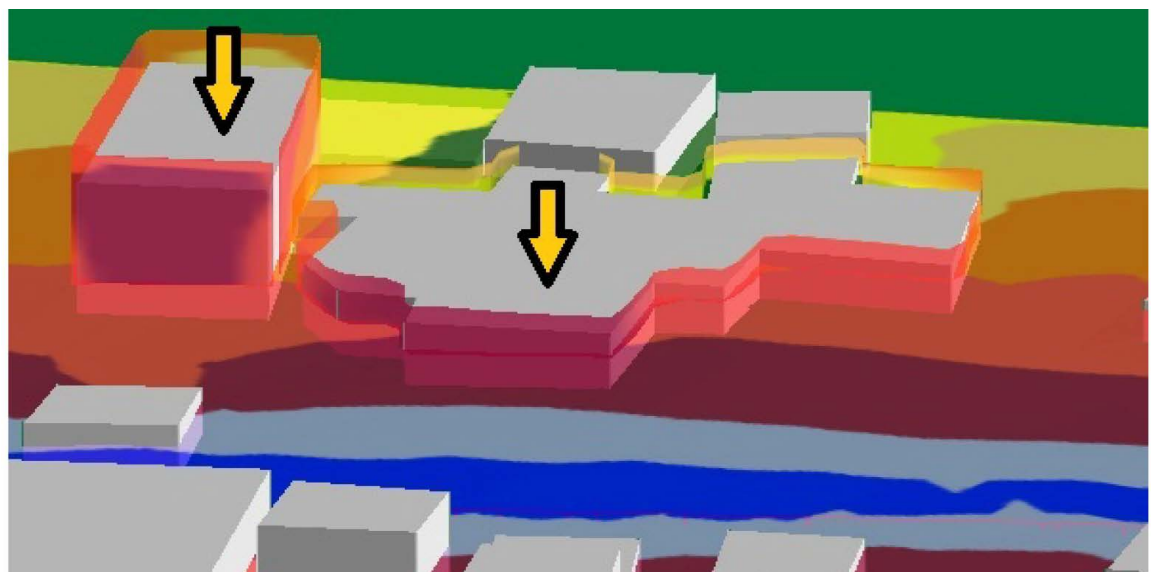

Figure 9. Noise levels that reach the facade of Santa Cruz Hospital.

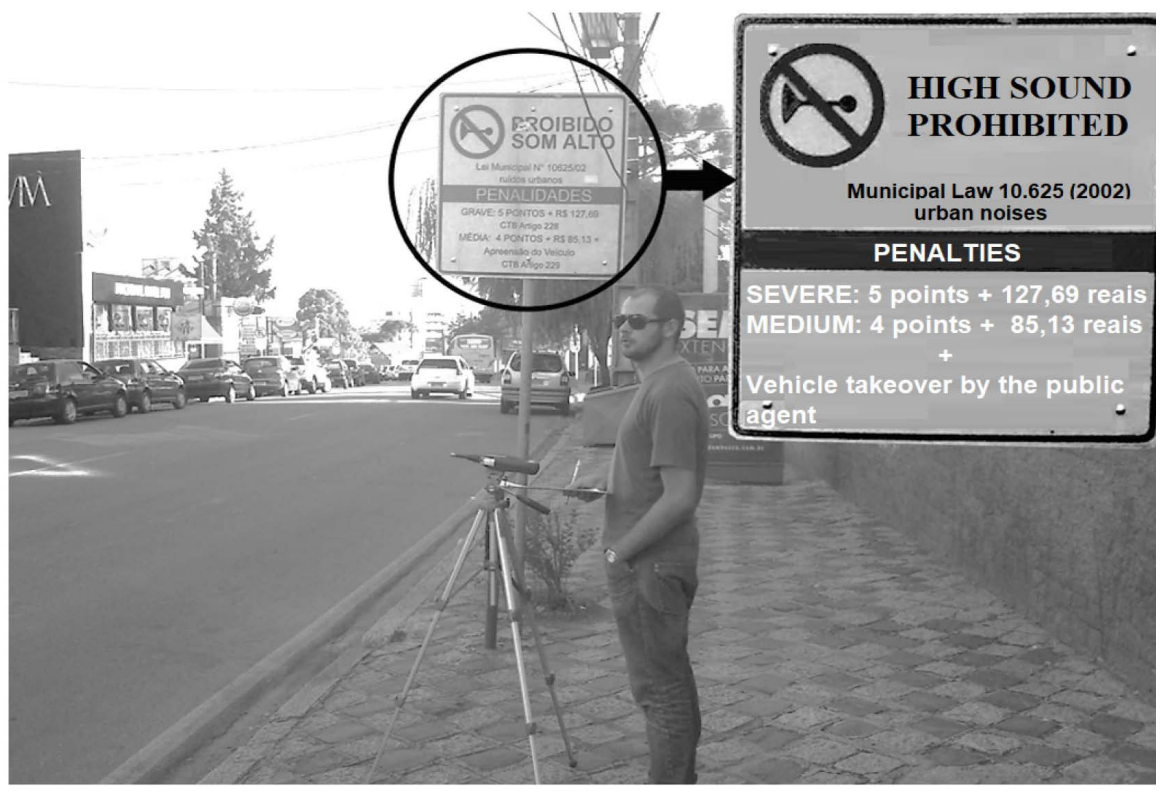

Figure 10. Batel Avenue plate indication

in the city, are strongly affected by street noise. These results from this study are in line with results found in Germany and Sweden [4], which were cited in the introduction.

One way to combating noise pollution is by applying pecuniary punishments, as can be seen on the plaque highlighted in Figure 10.

Figure 10 shows a plaque positioned on Batel Avenue, where it can be read: "Proibido Som Alto" [High Sound Prohibited]. It can also be seen on the plaque, the indicative penalties provided for in Municipal Law 10.625 (2002)_"ruídos urbanos" [urban noises] [6]. The penalties are in a range of medium to severe. Severe punishment can lead to vehicle takeover by the public agent.

\section{Conclusions}

This study found that the sound pressure levels today exceed the values recom- 
mended by Curitiba Municipal Law No. 10625. Therefore, the thoroughfares under study and their surrounding regions are in noncompliance with this law and are characterized by noise pollution. This study found that the street noise in these two majors and very important thoroughfares are constant and intense during the day period.

The fight against noise pollution involves urban planning and management. To improve people's quality of life, municipal authorities should maintain ongoing control of noise levels in the city and continuously calculate the city's noise maps, especially for "Quiet Zones". Lastly, using all the data acquired, the creation of a database is planned, so that data can be consulted to determine whether the levels of noise pollution have increased or decreased whenever mitigative measures are adopted.

\section{Acknowledgements}

The authors gratefully acknowledge the German Government, through the German Academic Exchange Service-DAAD (Deutscher Akademischer Austauschdienst) and the Brazilian Government, through the National Council for Scientific and Technological Development-CNPq, for their financial support, which enabled the purchase of the sound level meters and software used in this study.

\section{Conflicts of Interest}

The authors declare no conflicts of interest regarding the publication of this paper.

\section{References}

[1] Votsi, N.-E.P., Mazaris, A.D., Kallimanis, A.S., Drakou, E.G. and Pantis, J.D. (2014) Landscape Structure and Diseases Profile: Associating Land Use Type Composition with Disease Distribution. International Journal of Environmental Health Research, 24, 176-187. https://www.tandfonline.com/doi/abs/10.1080/09603123.2013.800965 https://doi.org/10.1080/09603123.2013.800965

[2] Booi, H. and van den Berg, F. (2012) Quiet Areas and the Need for Quietness in Amsterdam. International Journal of Environmental Research and Public Health, 9 , 1030-1050. https://www.mdpi.com/1660-4601/9/4/1030 https://doi.org/10.3390/ijerph9041030

[3] Paneto, G.G., Alvarez, C.E. and Zannin, P.H.T. (2017) Relationship between Urban Noise and the Health of Users of Public Spaces-A Case Study in Vitoria, ES, Brazil. Journal of Building Construction and Planning Research, 5, 45-57. https://doi.org/10.4236/jbcpr.2017.52004

[4] Fiedler, K. and Wilhelm, M. (2011) Hygiene/Medical/Preventive Environmental Medicine. UNI-MED Verlag AG, Bremen, London, Boston, 2. (In German)

[5] Associação Brasileira de Normas Técnicas (ABNT) (2000) Brazilian Association of Technical Standards (ABNT) NBR 10.151: Acoustics-Noise Assessment in Inhabited Areas Aiming at the Community's Comfort-Procedure. Rio de Janeiro. (In Portuguese)

[6] Law No. 10625 of 19 Dec 2002. Establishes Regulations on Urban Noise, Public 
Protection and Welfare, and Makes Other Provisions (9 p.) Diário Oficial do Estado do Paraná. (In Portuguese)

[7] Law No. 9.800 of 03 January 2000. Establishes Regulations on Urban Planning, Public Protection and Welfare, and Makes Other Provisions. Diário Oficial do Estado do Paraná. (in Portuguese)

[8] Romeu, J., Genescà, M., Pàmines, T. and Jimménez, S. (2011) Street Categorization for the Estimation of Day Levels Using Short-Term Measurements. Applied Acoustics, 72, 569-577. https://doi.org/10.1016/j.apacoust.2010.09.012

[9] Zannin, P.H.T. and Sant'Ana, D.Q. (2011) Noise Mapping at Different Stages of a Freeway Redevelopment Project-A Case Study in Brazil. Applied Acoustics, 72, 479-486. https://doi.org/10.1016/j.apacoust.2010.09.014

[10] Zannin, P.H.T., Engel, M.S., Fiedler, P.E.K. and Bunn, F. (2013) Characterization of Environmental Noise Based on Noise Measurements, Noise Mapping and Interviews: A Case Study at a University Campus in Brazil. Cities, 31, 317-327. https://doi.org/10.1016/j.cities.2012.09.008

[11] Paiva, K.M., Cardoso, M.R.A. and Zannin, P.H.T. (2019) Exposure to Road Traffic Noise: Annoyance, Perception and Associated Factors among Brazil's Adult Population. Science of the Total Environment, 650, 978-986. https://doi.org/10.1016/j.scitotenv.2018.09.041

[12] Guedes, M. and Leite, M.J. (2011) Guidelines for Elaboration of Noise Maps. Institute of Environment, Amadora. (In Portuguese)

[13] Bunn, F. and Zannin, P.H.T. (2015) Urban Planning-Simulation of Noise Control Measures. Noise Control Engineering Journal, 63, 1-10. https://doi.org/10.3397/1/376301

[14] Fiedler, P.E.K. and Zannin, P.H.T. (2015) Evaluation of Noise Pollution in Urban Traffic Hubs-Noise Maps and Measurements. Environmental Impact Assessment Review, 51, 1-9. https://doi.org/10.1016/j.eiar.2014.09.014

[15] EU (2002) Directive 2002/49/EC Relating to the Assessment and Management of Environmental Noise. Official Journal of the European Communities. No. L189.

[16] Murphy, E. and King, E.A. (2010) Strategic Environmental Noise Mapping: Methodological Issues Concerning the Implementation of the EU Environmental Noise Directive and Their Policy Implications. Environment International, 36, 290-298. https://doi.org/10.1016/j.envint.2009.11.006

[17] Licitra, G. and Memoli, G. (2008) Limits and Advantages of Good Practice Guide to Noise Mapping. Forum Acusticum, Paris. https://doi.org/10.1121/1.2932687

[18] Bies, D.A. and Hansen, C.H. (2002) Engineering Noise Control: Theory and Practice. 2nd Edition, Spon Press, Taylor and Francis Group, New York.

[19] Lee, S.W., Chang, S.I. and Park, Y.M. (2008) Utilizing Noise Mapping for Environmental Impact Assessment in a Downtown Redevelopment Area of Seoul, Korea. Applied Acoustics, 69, 704-714. https://doi.org/10.1016/j.apacoust.2007.02.009

[20] Zannin, P.H.T. and Ferraz, F. (2016) Assessment of Indoor and Outdoor Noise Pollution at a University Hospital Based on Acoustic Measurements and Noise Mapping. Open Journal of Acoustics, 6, 71-85. https://doi.org/10.4236/oja.2016.64006

[21] Zannin, P.H.T., Milanez, M.L. and de Oliveira Filho, M.V.M. (2019) Evaluation of Noise in the Vicinity of a Hospital and a Gated Community. Current Urban Studies, 7, 59-75. https://doi.org/10.4236/cus.2019.71004

[22] Brusch-Vishnica, I., West, J., Barnhill, C., Hunter, T., Orellana, D. and Chivukula, 
R. (2005) Noise Levels in Johns Hopkins Hospital. Journal Acoustical Society of America, 118, 3629-3645. https://doi.org/10.1121/1.2118327

[23] IPPUC Institute of Research and Urban Planning of Curitiba (2010) Research and Urban Planning Institute of Curitiba. (In Portuguese)

http://populacao.net.br/populacao-batel_curitiba_pr.html

[24] WHO (2011) Burden of Disease from Environmental Noise-Quantification of Healthy Life Years Lost in Europe. WHO Regional Office for Europe, Copenhagen, 58. 